OPEN

SUBJECT AREAS:

PHYLOGENETICS

PALAEONTOLOGY

Received

28 October 2014

Accepted

16 February 2015

Published

19 March 2015

Correspondence and requests for materials should be addressed to L.E.Z. (lindsay.zanno@ naturalsciences.org)

* These authors contributed equally to this work.

\section{Early crocodylomorph increases top tier predator diversity during rise of dinosaurs}

\author{
Lindsay E. Zanno ${ }^{1,2 *}$, Susan Drymala ${ }^{1,2 *}$, Sterling J. Nesbitt ${ }^{3} \&$ Vincent P. Schneider
}

\begin{abstract}
${ }^{1}$ Research \& Collections, North Carolina Museum of Natural Sciences, Raleigh, NC 27601, USA, ${ }^{2}$ Department of Biological Sciences, North Carolina State University, Raleigh, NC 27607, USA, ${ }^{3}$ Department of Geosciences, Virginia Polytechnic Institute and State University, Blacksburg, VA 24061, USA.
\end{abstract}

Triassic predatory guild evolution reflects a period of ecological flux spurred by the catastrophic end-Permian mass extinction and terminating with the global ecological dominance of dinosaurs in the early Jurassic. In responding to this dynamic ecospace, terrestrial predator diversity attained new levels, prompting unique trophic webs with a seeming overabundance of carnivorous taxa and the evolution of entirely new predatory clades. Key among these was Crocodylomorpha, the largest living reptiles and only one of two archosaurian lineages that survive to the present day. In contrast to their existing role as top, semi-aquatic predators, the earliest crocodylomorphs were generally small-bodied, terrestrial faunivores, occupying subsidiary (meso) predator roles. Here we describe Carnufex carolinensis a new, unexpectedly large-bodied taxon with a slender and ornamented skull from the Carnian Pekin Formation $(\sim 231 \mathrm{Ma})$, representing one of the oldest and earliest diverging crocodylomorphs described to date. Carnufex bridges a problematic gap in the early evolution of pseudosuchians by spanning key transitions in bauplan evolution and body mass near the origin of Crocodylomorpha. With a skull length of $>50 \mathrm{~cm}$, the new taxon documents a rare instance of crocodylomorphs ascending to top-tier predator guilds in the equatorial regions of Pangea prior to the dominance of dinosaurs.

$\mathrm{T}$ he composition of modern ecosystems can be traced to the dynamic recovery of life in the aftermath of the catastrophic end-Permian mass extinction ${ }^{1}$. During the Triassic Period, unstable biotic communities ${ }^{2}$ and morphing ecospace ${ }^{3}$ gave rise to extant vertebrate clades such as frogs, lizards, mammals, turtles, and dinosaurs ${ }^{1,4,5}$ and spurred seemingly unbalanced trophic assemblages dominated by an excess of predatory taxa $^{6}$. In the Middle Triassic, terrestrial predator assemblages included the small-bodied mesopredators Gracilisuchidae $^{7}$ and top tier predator guilds dominated by poposauroids and basal loricatans ("rauisuchians") ${ }^{8}$. By the Late Triassic, subsidiary predator guilds had shifted composition to newly emerging clades such as ornithosuchids ${ }^{9}$, early dinosaurs ${ }^{4,5}$, and the oldest known crocodylomorphs ${ }^{10}$. Whereas apex predator guilds were thought to be more highly conserved, retaining Middle Triassic representatives and expanding to include large-bodied theropod dinosaurs and rauisuchids.

Here we describe a new species of crocodylomorph from the Carnian Pekin Formation, North Carolina, USA, representing one of the oldest, largest, and most basal crocodylomorphs yet discovered. This new taxon adds to a growing body of evidence that Triassic crocodylomorphs were more diverse than previously appreciated, and that theropod dinosaurs and crocodylomorphs exploited a wide trophic reach ${ }^{11}$, occupying both subsidiary and toptier predator roles in the Late Triassic.

\section{Results}

Systematic paleontology. Archosauria Cope, 1869. Pseudosuchia Zittel, 1887-1890. Crocodylomorpha Walker, 1968 sensu Nesbitt 2011. Carnufex carolinensis gen. et sp. nov.

Etymology. Carnufex (Latin) butcher; carolinensis, in reference to the region of discovery.

Holotype. NCSM 21558, partial skull and postcranial skeleton including: right dentigerous premaxilla, left maxilla, left lacrimal, left jugal, left articular, right angular, isolated maxillary tooth, cervical neural arch, dorsal neural arch, cervical rib, dorsal ribs, and left humerus. (Fig. 1, S9). 


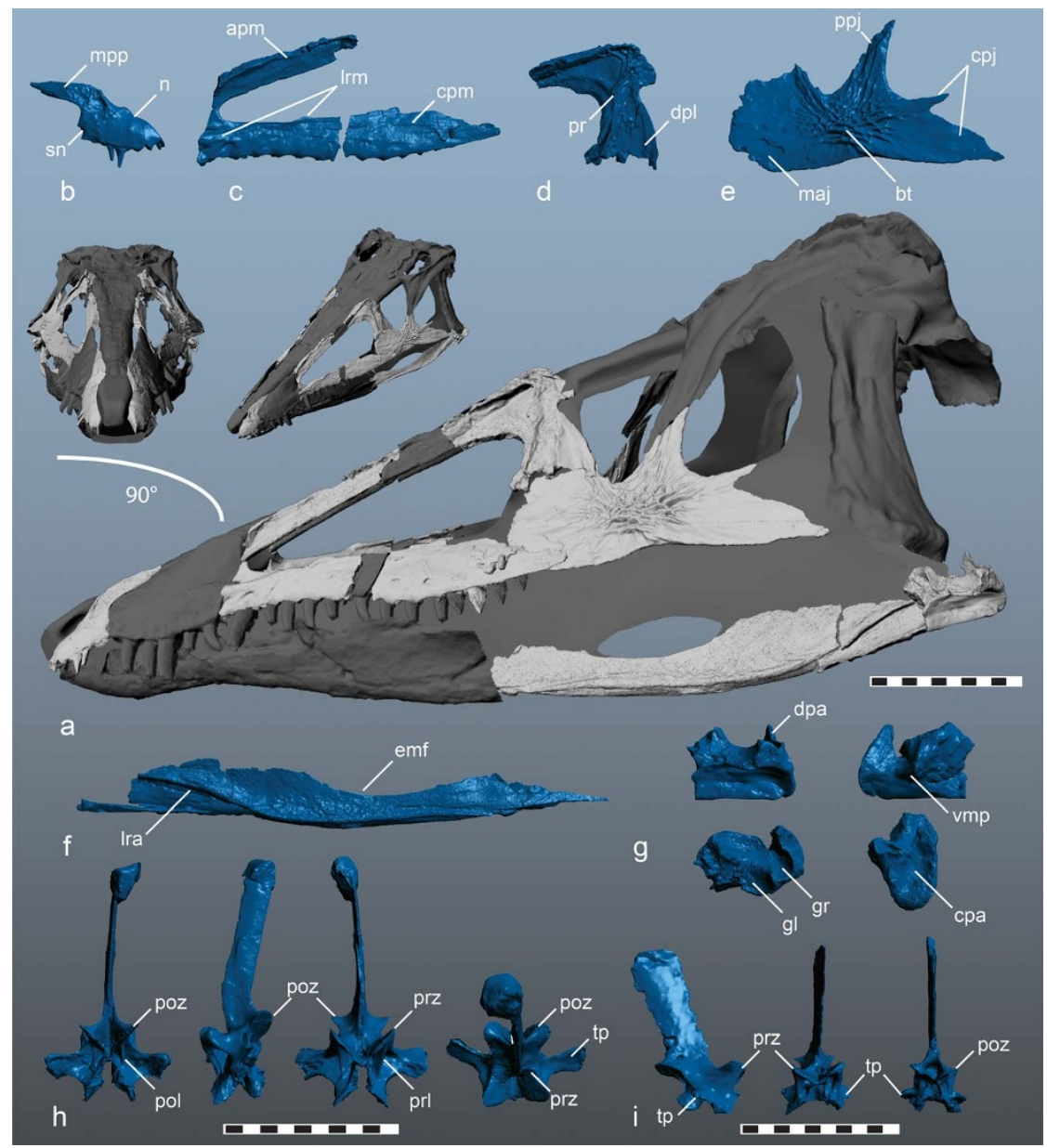

Figure $1 \mid$ Three dimensional skull reconstruction and representative elements of Carnufex carolinensis (NCSM 21558). (a) reconstructed skull, clockwise from upper left, rostral, oblique, and lateral views; (b) right premaxilla, lateral view; (c) left maxilla, lateral view; (d) left lacrimal, lateral view; (e) left jugal, lateral view; (f) right angular, lateral view; (g) left articular, in (clockwise from upper left) lateral, medial, dorsal, caudal views; (h) cervical neural arch, in (left to right) caudal, lateral, cranial, and dorsal views; (i) dorsal neural arch, in (left to right) right lateral, cranial, and caudal views. Abbreviations: apm, ascending process, maxilla; bt, bulbous tuberosity; cpa, caudal process, articular; cpj, caudal process, jugal; cpm, caudal process, maxilla; dpa, dorsal process, articular; dpl, descending process, lacrimal; emf, external mandibular fenestra; gl, glenoid, gr, groove; lra, lateral ridge, angular; lrm, lateral ridge, maxilla; maj, maxillary articulation, jugal; mpp, maxillary process, premaxilla; $\mathbf{n}$, naris; pol, centropostzygapophyseal lamina; poz, postzygapophysis; ppj, postorbital process, jugal; pr, prong; prl, centroprezygapophyseal lamina; prz, prezygapophysis; sn, subnarial notch; tp, transverse process; vmp, ventromedial process. Scale bar: $10 \mathrm{~cm}$.

Referred materials. NCSM 21623, partial right humerus.

Locality and horizon. Chatham County, North Carolina, USA; Pekin Formation, Chatham Group, Newark Supergroup, $\sim 231 \mathrm{Ma}^{12}$, Carnian, Late Triassic (SI-II).

Diagnosis. Large-bodied $(\sim 3 \mathrm{~m})$ crocodylomorph distinguished by the following features (loricatan autapomorphies denoted by an asterisk): six premaxillary teeth*; horizontally directed maxillary process of premaxilla; elongate, subtriangular antorbital fenestra (length to height ratio $\sim 2.3$ ); caudodorsally trending lateral ridge on maxilla terminates at margin of antorbital fenestra*; caudal process of maxilla rostrally pinched, minimum dorsoventral height at rostralmost corner of antorbital fenestra*; jugal with ornamented lateral boss*; caudally deep antorbital fossa, with anteriorly directed flange extending from rostral margin of lacrimal*; caudal margin of antorbital fossa vertically oriented (caudodorsal corner directly dorsal to caudoventral corner)*; antorbital fossa more than twice the estimated area of the orbit*; bifurcated caudal process of jugal bearing a small caudodorsally directed flange*; small, sub-conical, medial process of articular; pronounced crainocaudally oriented ridge on caudal aspect of lateral surface of angular; ectepicondylar crest proximal to the radial condyle of the humerus.

Description. All neurocentral sutures remain open in NCSM 21558 indicating a skeletally immature individual ${ }^{13}$. The skull is rostrally elongate (estimated minimum length $>50 \mathrm{~cm}$ ) and lightly built (Fig. 1a). The maxillary process of the premaxilla projects horizontally; it is subequal in length and parallel with, the alveolar margin (Fig. 1b). The premaxilla bears six premaxillary teeth (Fig. S9b), and a subnarial notch along the caudoventral margin of the tooth row (Fig. 1b, S1) as in Dromicosuchus ${ }^{14}$ NCSM 13733 (formerly UNC 15574 ), and the early crocodylomorph CM 29894. The palatal process exhibits a rostral palatal foramen (for the fourth dentary tooth $\left.^{15}\right)$.

The antorbital fenestra is hypertrophied, circumscribed by a weakly developed antorbital fossa (Fig. 1c, S2) that contrasts with the expanded fossa and reduced fenestra of other loricatans and resembles that of poposauroids (e.g., Arizonasaurus) and early dinosaurs. The maxilla of Carnufex is transitional in possessing a straplike, elongate ascending process at least $2 / 3$ rds the length of the antorbital fenestra. This is an intermediate condition between the 
craniocaudally reduced ascending process of other early diverging crocodylomorphs (e.g., Dromicosuchus ${ }^{14}$, Sphenosuchus ${ }^{16}$ ), and the relatively elongate, yet caudally expanded, ascending process of rauisuchids (e.g., Polonosuchus ${ }^{17}$ ).

A well-defined, rugose lateral ridge on the jugal process of the maxilla rises sharply to terminate at the ventral margin of the rostral antorbital fenestra (Fig. 1c), a condition otherwise undocumented in loricatans. A rugose, rostrally-oriented ridge on the rostral margin of the lacrimal bears a subtriangular prong, forming a keyhole shaped caudal margin of the antorbital fossa (Fig. 1d, S3). The descending process of the lacrimal widens rostrocaudally to contact the expanded rostral process of the jugal near the ventral orbital margin (Fig. 1a) as in crocodylomorphs. However, unlike crocodylomorphs, the ventral portion of the orbit in Carnufex is craniocaudally compressed, a condition that more closely resembles rauisuchids. The orbital area is markedly smaller than the antorbital fossa $(<50 \%)$. The caudal process of the jugal is bifurcated (Fig. 1e, S4), a synapomorphy of Dinosauria, also present in Proterosuchus ${ }^{18}$.

The angular is slender and rims an elongate external mandibular fenestra (minimum $10 \mathrm{~cm}$ in length). In lateral view, the caudal aspect folds into a pronounced ridge (Fig. 1f. S5) as in Junggarsuchus ${ }^{19}$, likely representing the insertion point for the $\mathrm{m}$. pterygoideus ventralis ${ }^{20}$. The articular bears a saddle-shaped glenoid, as in crocodylomorphs generally. A ventromedial process of the articular is present, yet reduced, differing from the tongue-like condition of other loricatan $\mathrm{s}^{21}$. The caudodorsal surface of the caudal process of the articular is concave as in Dromicosuchus ${ }^{14}$ and Protosuchus richardsoni and bears a dorsomedial projection as in other basal crocodylomorphs ${ }^{14,16}$. In Carnufex, this projection is separated from the glenoid by a deep groove (Fig. 1g, S6) that is otherwise absent in crocodylomorphs more closely related to Crocodyliformes ${ }^{18}$.

Premaxillary tooth crowns are elongate, serrated, and slightly recurved, whereas the caudal maxillary tooth is serrated on mesial and distal carinae, stout and blade-like, with a weakly convex distal carina. All cranial elements except the articular are ornamented. Anastomosing pits and grooves are most pronounced on the jugal, where they form a rounded tuberosity (Fig. 1e), and on the lacrimal, where they coalesce into a rugose crest on the caudodorsal margin of the antorbital fossa (Fig. 1d). The large bodied, crocodylomorph Redondavenator also exhibits pronounced cranial ornamentation ${ }^{11}$, as do some large-bodied rauisuchids (e.g., Postosuchus ${ }^{22}$ ). Ornamentation is weak to absent in small-bodied basal crocodylomorphs (e.g., Sphenosuchus ${ }^{16}$, Dromicosuchus ${ }^{14}$ ) suggesting a possible correlation with body size.

The cervical neural arch (Fig. 1h, S7) exhibits dorsoventrally expanded diapophyses; and transversely elongate, steeply inclined pre- and postzygapophyses. Nine bilateral laminae support the neural arch, framing infrapre- and infrapostzygapophyseal fossae and centrodiapophyseal fossae, with accessory divisions. A single dorsal neural arch possesses centroprezygapophyseal fossae and diminutive, pendant transverse processes (Fig. 1i, S8). The humerus is relatively short ( $<45 \%$ of estimated skull length), with a transversely expanded distal end that is proportionally consistent with rauisuchids ( $\sim 300 \%$ shaft width), as opposed to crocodylomorphs $(<200 \%)$. An ectepicondylar groove and a supinator process are present, as in aetosaurs, other loricatans, yet in contrast to other crocodylomorphs.

\section{Discussion}

A comprehensive phylogenetic analysis of Archosauria including 79 taxa and 413 characters $^{7}$ posits Carnufex at the base of Crocodylomorpha in an unresolved polytomy with the skeletally immature postcranial skeleton CM 73372 (Fig. 2a, S9). We also provide the first phylogenetic placement of the Rhaetian pseudosuchian Redondavenator, substantiating this taxon as the largest Triassic crocodylomorph yet described ${ }^{11}$ (Fig. S9). Carnufex and Redondavenator expand the diversity of top tier terrestrial predator guilds in the Late Triassic to at least five distinct archosaur clades and document vast overlap in body size between contemporary dinosaurs and crocodylomorphs (Fig. 2b). In contrast, the Triassic-Jurassic transition marks a shift to dichotomous body mass distributions between terrestrial members of these two clades, and a loss of top tier crocodylomorph diversity after the end-Triassic extinction (ETE) (Fig. 2b).

The Carnian-aged Pekin Formation preserves some of the oldest Triassic archosaur assemblages in North America and brings to bear unique biodiversity data on the composition of top predator guilds preceding the appearance of theropod dinosaurs on the continent $^{18,23}$. To date, tetrapods of the Pekin Formation are well sampled, and capture a diverse assemblage comprised of dicynodontians ${ }^{24}$, traversodontid cynodontians $s^{25}$, aetosaurians ${ }^{26}$, and two species of crocodylomorphs (Carnufex, and a new small bodied taxon ${ }^{27}$ with a femur length $\{$ FL $\}=133 \mathrm{~mm}$ ) (Fig. 2c). With an estimated immature FL of 353-440 mm, Carnufex is the largest terrestrial predator in the Pekin Formation (Fig. 2d), vastly exceeding the body size of the earliest North American theropod dinosaurs (FL 174-265 mm) (Fig. 2b).

Early concepts of faunal homogenization across Pangea are unsupported by recent studies, which instead document latitudinally arrayed, paleoclimatic faunal provinces across the supercontinent ${ }^{12,28}$, although this pattern is likely restricted to assemblages preceding the $\mathrm{ETE}^{29}$. Predatory guild evolution in the Triassic was equally complex, with recent research supporting a diachronous replacement of the leading terrestrial predators-pseudosuchianswith theropod dinosaurs between proto-Laurasian and Gondwanan landmasses ${ }^{23,30}$. Our chronostratigraphic plots of body size (Fig. 2b) and paleogeographic region (Fig. 2d) support both hypotheses. Whereas Carnian terrestrial predator guilds in southern hemisphere faunas were exploited in part by large bodied theropod dinosaurs, northern and equatorial faunas of similar age have yet to yield definitive theropod remains ${ }^{5,23,30}$ and appear instead to have been evolutionary centers for large bodied terrestrial crocodylomorphs ${ }^{11}$, as exemplified by Carnufex in the Carnian and subsequently by Redondavenator in the Rhaetian. The loss of large-bodied crocodylomorphs nearing the ETE may have spurred mesopredator release $^{31}$ or opportunistic invasion scenarios ${ }^{30}$, whereby smaller-bodied theropods subsequently assumed apex predator roles in paleoequatorial regions of proto-Laurasia.

\section{Methods}

Body size. We evaluated body size using the widely accepted proxy of femur length $(\mathrm{FL})^{32-34}$. Measurements of FL were derived primarily from recent archosaurian datasets $^{32,35}$. Select taxa relevant to our analyses lack a femur and required FL estimation. We derived scaling equation (1) for predicting FL by applying OLS regression analysis on bivariate plots of FL/humeral length (HL) (Fig. S10) and equation (2) using FL/skull length (SKL) (Fig. S11) for a variety of loricatans for which data were available (Table S1). We also performed OLS regressions on bivariate plots of log e HL against SKL (Fig. S12) to examine the reliability of our estimates against independent scaling relationships (equation [3]). Data was log transformed (log e). Scaling equations had high coefficients of determination $\left(\mathrm{R}^{2}\right)$ ranging from $0.94-0.97$; however, these are influenced by low sample size $(\mathrm{n}=12)^{36}$.

$$
\begin{aligned}
& \ln (\mathrm{y})=\ln (\mathrm{x}) 0.8136+0.5615\left(\mathrm{R}^{2}=0.9482\right) \\
& \mathrm{y}=\mathrm{FL}, \mathrm{x}=\mathrm{HL} \\
& \ln (\mathrm{y})=\ln (\mathrm{x}) 1.0616-0.2484\left(\mathrm{R}^{2}=0.97273\right) \\
& \mathrm{y}=\mathrm{FL}, \mathrm{x}=\mathrm{SKL} \\
& \ln (\mathrm{y})=\ln (\mathrm{x}) 1.2362-0.6436\left(\mathrm{R}^{2}=0.93687\right) \\
& \mathrm{y}=\mathrm{HL}, \mathrm{x}=\mathrm{SKL}
\end{aligned}
$$

We used scaling equations to estimate FL of Trialestes romeri based on a $220 \mathrm{~mm}$ measurement of SKL provided by Reig ${ }^{37}$; Redondavenator quayensis based on a $600 \mathrm{~mm}$ SKL estimate provided by Nesbitt et al. ${ }^{11}$; Pseudhesperosuchus jachaleri based on an estimated skull length of $130 \mathrm{~mm}^{38}$, Dibrothosuchus elaphros based on 


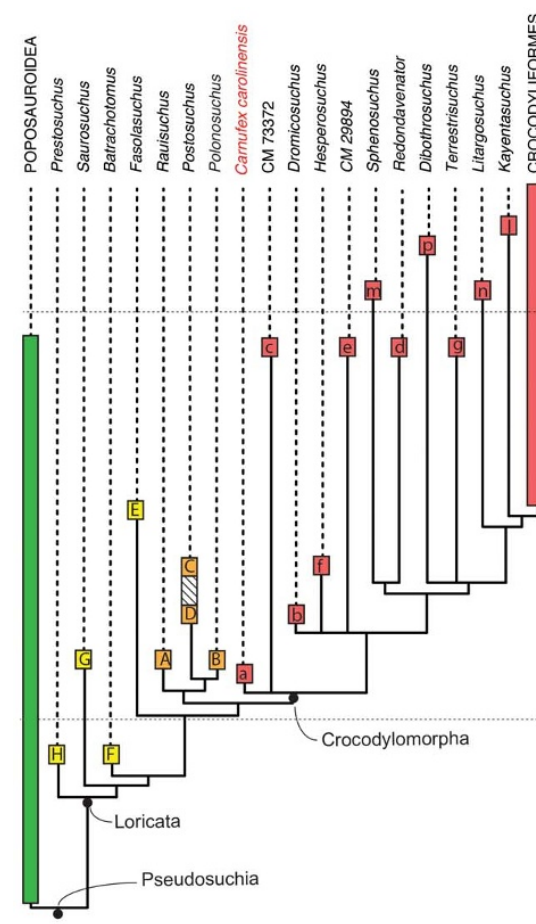

a
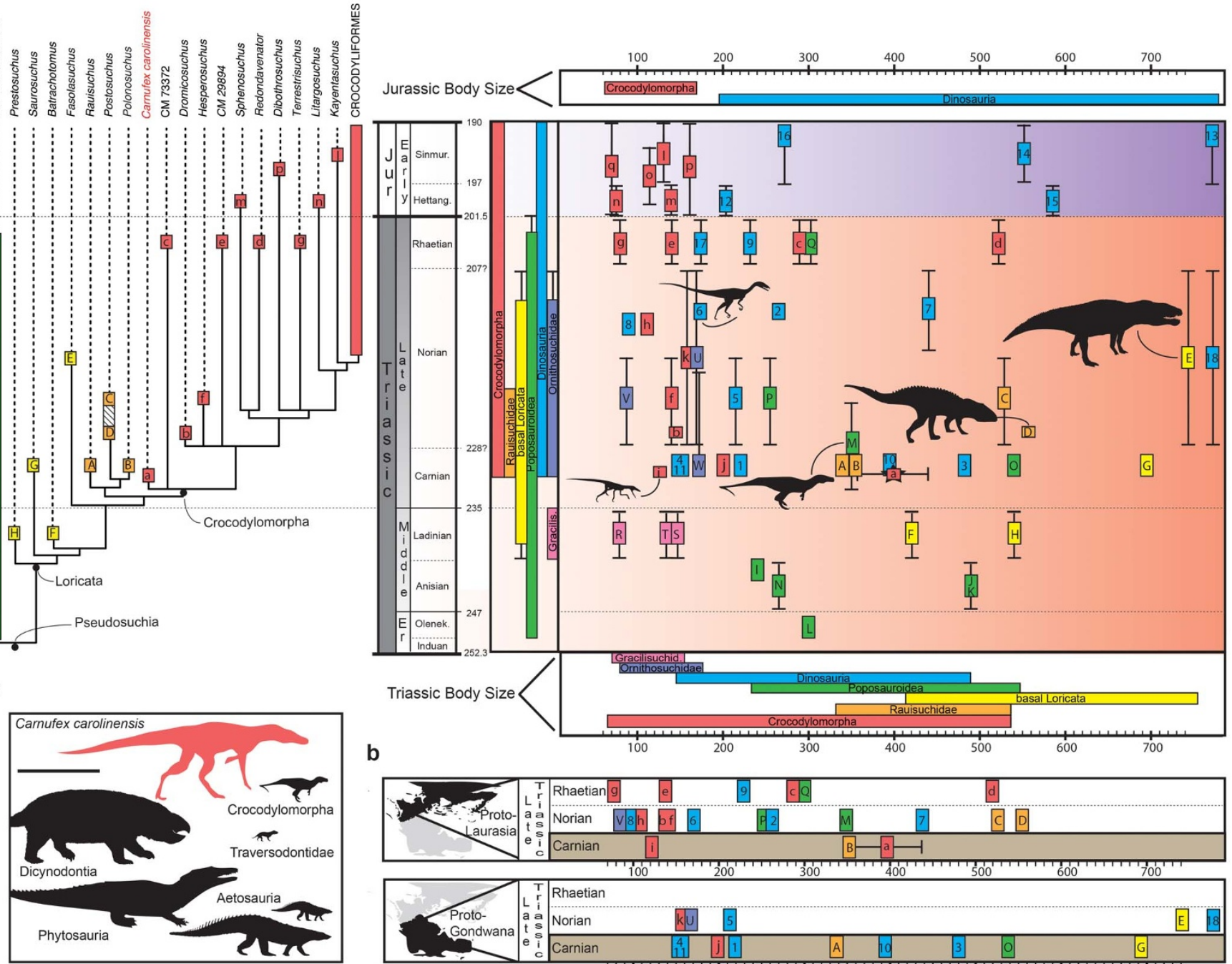

b

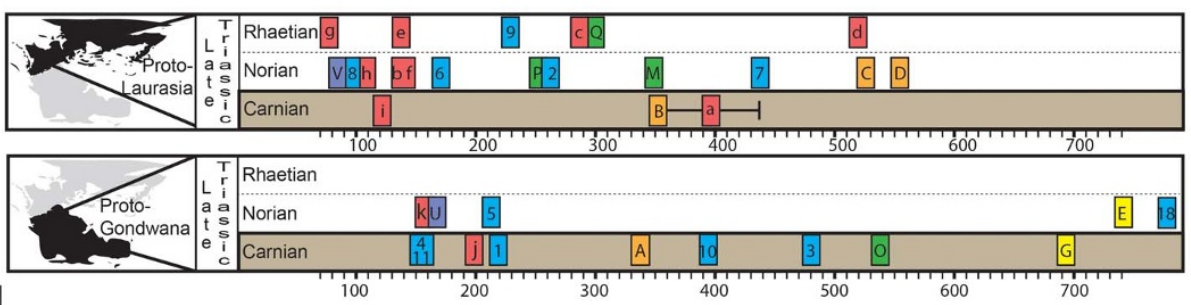

C

d

Figure 2 Evolutionary relationships, chronostratigraphic distribution, and estimated body size for putatively terrestrial, carnivorous archosaurians of the Triassic and earliest Jurassic. (a) Chronostratigraphically calibrated strict consensus tree showing taxonomy and relationships of the pseudosuchian clade Loricata. Carnufex carolinensis posited as a basalmost crocodylomorph. (b) Chronostratigraphically calibrated, bivariate plots of body size in terrestrial carnivorous archosaur clades with clade-specific temporal distributions summarized on the y-axis, and Triassic and earliest Jurassic body size ranges summarized on lower and upper x-axes, respectively. (c) Body size distribution in the Triassic divided by proto-Laurasia and protoGondwana. (d) Tetrapod composition of the Carnian-aged Pekin Formation ( $\sim 231 \mathrm{Ma})$ to scale. Size estimates based on the proxy femur length (FL) in $\mathrm{mm}$. Error bars denote stratigraphic and FL uncertainty. Key for taxon symbols a-q; A-V; 1-18 in Table S2. Taxon colors consistent between subparts. Paleomaps produced in Adobe Photoshop CS5.1. Scale bar in subpart (c) $=1 \mathrm{~m}$.

$112.5 \mathrm{~mm} \mathrm{HL}$ and $164 \mathrm{~mm} \mathrm{SKL}{ }^{15}$, Phyllodontosuchus lufengensis based on a $71.5 \mathrm{~mm}$ $\mathrm{SKL}^{39}$, Pedeticosaurus leviseuri based on a $\mathrm{HL}$ of $82 \mathrm{~mm}^{40}$, Yonghesuchus sangbiensis based on a $155 \mathrm{~mm} \mathrm{SKL}^{7}$. We used comparative SKL to FL measurements provided by Sues et al. ${ }^{41}$ and Smith et al. ${ }^{42}$ to approximate the FL of Daemonosaurus chauliodus and Zupaysaurus rougieri. At $145 \mathrm{~mm}$, the SKL of D. chauliodus closely approximates the estimated SKL of Tawa hallae $\left(147 \mathrm{~mm}^{41}\right)$, whereas, the estimated SKL of $Z$. rougieri closely approximates that of Cryolophosaurus ellioti (FL $769 \mathrm{~mm}^{42}$ ). We did not estimate FL of the Early Jurassic theropods Dracovenator regenti and Lophostropheus airelensis because of the fragmentary nature of the remains (all lack appendicular elements and complete skulls) and because our conclusions revolve around Late Triassic fauna in the former instance. However, we note that published estimates of $D$. regenti size (5.5-6.5 $\mathrm{m}$ in length ${ }^{42}$ ) would place this taxon with the range of body size already captured in Figure 2, adding no new data to our results. Estimates of FL generated for these taxa are listed in Table S2 and marked with an asterisk. We only provide a general estimate of FL for the ornithosuchid

Venaticosuchus as approximating that of the ornithosuchid Riojasuchus, because the skull of this taxon is highly fragmentary and appears to have been close in size to Riojasuchus 9 .

We derived a FL range for Carnufex carolinensis of 354-441 mm, based on a measured HL of $207.7 \mathrm{~mm}$ and estimated minimum SKL of $500 \mathrm{~mm}$, respectively. Given the large FL range produced from these two variables, we further explored FL for Carnufex by testing how accurately we could approximate known HL and estimated SKL values using the relevant scaling equation derived from our loricatan dataset. Our estimation of Carnufex HL using a minimum SKL length of $500 \mathrm{~mm}$ was $257 \mathrm{~mm}, 24 \%$ larger than our actual measurement on the preserved humerus of NCSM 21558. Conversely, our estimate of Carnufex SKL using the actual value for HL of CNSM 21558 was $385 \mathrm{~mm}$, far shorter than the portion of the skull preserved $(450 \mathrm{~mm})$. These data indicate that the humeral to skull proportions of Carnufex are not a good fit to the regression, i.e., either the humerus of Carnufex is unusually short, or the skull unusually long, or both variations are compounded. Therefore, we present FL estimates derived both from the HL and SKL here. We note that NCSM 21558 is skeletally immature, having open neurocentral sutures across the cervical and dorsal series minimally. This immaturity plus our use of a minimum estimate for skull length yields a conservative range of $354-441 \mathrm{~mm}$ for FL. We expect the FL of a somatically mature Carnufex would fall within the upper values of our current estimates or perhaps well above. Our gross estimate of the body length of a skeletally immature Carnufex $(\sim 3 \mathrm{~m})$ is based on comparative skeletal ratios in the closely related Dromicosuchus (NCSM 13731) and the nearly complete basal crocodylomorph NCSM $21722^{27}$.

Ecological inferences. Given that autecology cannot be observed for extinct taxa, paleontologists generally rely on the presence of ecomorphological traits to infer dietary inferences ${ }^{43-46}$ and construct trophic networks ${ }^{2,48,49}$. We follow Mitchell \& Makovicky ${ }^{49}$ in assigning the extinct archosaurs to guilds (e.g., top-tier predator) 
based on body size, inferred diet, and habitat (e.g., terrestrial, semi-aquatic, aquatic). These ecological factors were taken from the published literature. We followed multiple authors in considering taxa of the following clades to represent the diversity of carnivorous, terrestrial, Triassic pseudosuchians: loricatans (Rauisuchidae + Crocodylomorpha) $)^{6,10}$, gracilisuchids ${ }^{7}$, poposauroids ${ }^{50}, \&$ ornithosuchids ${ }^{9}$; and in assigning early theropods to this guild ${ }^{5}$. Dietary inferences for some Triassic pseudosuchians are ambiguous (e.g., Effigi ${ }^{51}$ ); however, without quantitative analyses testing analogous ecomorphological traits in these taxa ${ }^{45,47}$, we include them as carnivores in keeping with the apparent dominant trophic habit of their clade, considering this a conservative approach. Currently known diversity places Carnufex and Redondavenator as the largest, terrestrial carnivores within their respective assemblages $^{11}$, which generally denotes apex predator status ${ }^{30}$. However, given the potential of sampling biases (e.g., no rauishuchids recovered from the Pekin Formation) and the nuances of extant predator interaction ${ }^{6,30}$, we refrain from restricting these taxa to apex predator roles. Rather, we adopt a more conservative approach that allows for incomplete sampling of large-bodied carnivores, by considering Carnufex and Redondavenator to be minimally, components of top-tier predator guilds within Triassic faunas.

Phylogenetic protocol. We examined the evolutionary relationships of Carnufex and Redondavenator by inclusion in the recent, comprehensive analysis of archosaurs published by Butler et al. ${ }^{7}$, which is an expansion of $\mathrm{Nesbitt}^{18}$. The analysis includes 79 archosaurs and 413 characters. We followed Butler et al. ${ }^{7}$ in a priori exclusion of the operational taxonomic units: Archosaurus rossicus, Prestosuchus chiniquensis, UFRGS 0156 T, UFRGS 0152 T, Lewisuchus admixtus, and Pseudolagosuchus major and in designation of the following characters as additive: $32,52,75,121,137,139$, $156,168,188,223,247,258,269,271,291,297,328,356,399$, and 413. Data coding, character tracing and tree manipulation/visualization were carried out using Mesquite ver. $2.75^{52}$. Phylogenetic analyses were executed in the program $\mathrm{TNT}^{53}$. We conducted heuristic searches on Wagner trees using TBR (tree bisectionreconnection) branch-swapping with 1,000 random addition sequences holding 10 trees per replicate, continuing subsequent TBR swapping on all stored minimum length trees (90 most parsimonious trees, TL 1,320). We assessed results using strict and reduced consensus methods and Bremer support values ${ }^{54}$. Ambiguous nodes were collapsed following Rule 1 of Coddington and Scharff ${ }^{5}$. Maximum agreement subtrees ${ }^{56}$ were calculated in TNT and used to identify labile taxa and common topology among all MPTs.

In this analysis we recover three unambiguous synapomorphies of Crocodylomorpha + Carnufex: a sub narial gap (char. 11 state 1); an elongate lacrimal reaching the ventral aspect of the orbit (char. 39, state 1); and loss of fin-like hyposphen-hypantrum articulations in the vertebral series (char. 195, state 0). However, Carnufex clearly exhibits a mosaic bauplan that spans lightly built, cursorial crocodylomorphs and their large-bodied, robust sister taxa, rauisuchids. As a result, Carnufex also shares several skeletal features characteristic of rauisuchids including a bulbous longitudinal ridge on the maxilla (char. 26, state 2); non-tapering dorsal process of the maxilla (char. 29, state 1); as well as retaining some synapomorphies of Loricata, lost in crocodylomorphs more closely related to Alligator than Carnufex, including a distinct groove caudal to the glenoid fossa on the articular (char. 156, state 1); and a tall, narrow orbit (char. 142, state 1). Carnufex also possesses some traits convergent with theropod dinosaurs such as a bifurcated caudal process of the jugal (char. 71, state 3 ) and a dorsoventrally expanded caudal process of the jugal, also present in Revueltosaurus and some archosauromorphs (char. 27, state 2). We recover Carnufex as an unequivocal crocodylomorph in our analysis. Two steps are required to move Carnufex out of Crocodylomorpha (Fig. S9). The remaining nodes within Crocodylomorpha are supported by Bremer values of 1 (Fig. S9). The mosaic morphology exemplified by this taxon and its basal phylogenetic and stratigraphic position yields critical insight into the step-wise appearance of the crocodylomorph bauplan.

Redondavenator quayensis was described as a large bodied crocodylomorph ${ }^{11}$, yet has not been tested in a phylogenetic context. Although fragmentary (only $8 \%$ of characters can be coded) we included this taxon to substantiate this placement quantitatively. Our analysis posits R. quayensis as sister-taxon to Sphenosuchus acutus based on the shared presence of an elongated maxillary process of the premaxilla (char 2, state 1). Although the maxillary process of the premaxilla is incomplete in Redondavenator, we find that all taxa possessing five or more maxillary alveoli anterior to the antorbital fenestra also possess a maxilla in which the portion rostral to the antorbital fenestra is longer than the posterior process (char 2, state 1) (SD per obs.). This correlation may not prove exhaustive, given that Redondavenator only includes the anterior portion of the skull; however, we include coded Redondavenator for this trait as a testable hypothesis.

The skeletally immature postcranial skeleton CM 73372 has been variously interpreted as Postosuchus ${ }^{28,57,58}$ and a Hesperosuchus-like basal crocodylomorph ${ }^{18}$. Our analysis is unable to resolve the relationship between Carnufex and CM 73372, recovering these taxa in a polytomy with a clade consisting of all remaining crocodylomorphs. Carnufex is represented predominantly by cranial elements and CM 73372 consists entirely of postcranial elements, therefore there is little overlapping data between these species to aid in phylogenetic resolution.

$3 \mathrm{D}$ visualization and reconstruction. Elements of the skull and postcranial skeleton of Carnufex were scanned using a Creaform EXAscan ${ }^{\mathrm{TM}}$ high-resolution $(0.050 \mathrm{~mm})$ handheld surface scanner. Scans were captured in 1.0-0.02 mm resolution using VXelements 3D data acquisition software. Post processing and generation of 3D
PDFs were accomplished in Geomagic Studio ${ }^{\circledR}$. We used Autodesk Maya 2014 to produce a composite three-dimensional model of the skull using individual element scans of Carnufex (NCSM 21623), supplemented with scaled surface scans of cranial elements of the closely related crocodylomorph Dromicosuchus, and Junggarsuchus, performed using the same protocol as Carnufex. Skull width was modeled using the relatively undeformed skull roof of Dromicosuchus. The rostral dentary and braincase were modeled using scans of Junggarsuchus, whereas the rostral maxilla, quadrate, frontals, parietals, squamosals, nasals, and maxillary dentition were modeled from Dromicosuchus. The circumnarial region of the premaxilla, prefrontal, quadratojugal and remainder of the mandible were generated as de novo objects manipulated to reflect estimated proportions. Original three-dimensional scans of the skeletal elements of Carnufex are provided as individual 3D PDFs as Supplementary Information (Figs. S1-8).

Methods summary. This published work and the nomenclatural acts it contains have been registered in ZooBank, the proposed online registration system for the International Code of Zoological Nomenclature (ICZN). The ZooBank LSIDs (Life Science Identifiers) can be resolved and the associated information viewed through any standard web browser by appending the LSID to the prefix 'http://zoobank.org/'. The LSID for this publication is: urn:lsid:zoobank.org:pub:129E5681-0D2E-4A7DBC04-A3E624151BF7.

1. Chen, Z.-Q. \& Benton, M. J. The timing and pattern of biotic recovery following the end-Permian mass extinction. Nature Geosci. 5, 375-383; DOI:10.1038/ NGEO1475 (2011).

2. Roopnarine, P. D., Angielczyk, K. D., Wang, S. C. \& Hertog, R. Trophic network models explain instability of Early Triassic terrestrial communities. Proc. Biol. Sci. 274, 2077-2086 (2007).

3. Bambach, R. K., Bush, A. M. \& Erwin, D. H. Autecology and the filling of ecospace: key metazoan radiations. Palaeontol. 50, 1-22 (2007).

4. Brusatte, S. L. et al. The origin and early radiation of dinosaurs Earth. Sci. Rev. 101, 68-100; DOI:10.1016/j.earscirev.2010.04.001 (2010).

5. Langer, M. C., Ezcurra, M. D., Bitterncourt, J. S. \& Novas, F. E. The origin and early evolution of dinosaurs. Biol. Rev. 85 (55-110) DOI:10.1111/j.1469185X.2009.00094.x (2010).

6. Drumheller, S. K., Stocker, M. R. \& Nesbitt, S. J. Direct evidence of trophic interactions among apex predators in the Late Triassic of western North America. Naturwiss. Published online 17 September; DOI:10.1007/s00114-014-1238-3 (2014).

7. Butler, R. J. et al. New clade of enigmatic early archosaurs yields insights into early pseudosuchian phylogeny and the biogeography of the archosaur radiation. BMC Evol. Biol. 14, 128 (2014).

8. Nesbitt, S. J. et al. [Rauisuchidae] Anatomy, phylogeny and palaeobiology of early archosaurs and their kin [Nesbitt, S. J., Desojo, J. B. \& Irmis, R. B. (eds)] [241-274] (Geol. Soc. Lond., London, 2013) DOI:10.1144/SP379.1.

9. von Baczko, M. B. \& Ezcurra, M. D. Ornithosuchidae: a group of Triassic archosaurs with a unique ankle joint] Anatomy, phylogeny and palaeobiology of early archosaurs and their kin [Nesbitt, S. J., Desojo, J. B. \& Irmis, R. B. (eds)] [187-202] (Geol. Soc. Lond., London, 2013) DOI:10.1144/SP379.4.

10. Irmis, R. B., Nesbitt, S. J. \& Sues, H.-D. [Early Crocodylomorpha] Anatomy, phylogeny and palaeobiology of early archosaurs and their kin [Nesbitt, S. J., Desojo, J. B. \& Irmis, R. B. (eds)] [275-302] (Geol. Soc. Lond., London, 2013) DOI:10.1144/SP379.24.

11. Nesbitt, S. J, Irmis, R. B, Lucas, S. G \& Hunt, A. P. A giant crocodylomorph from the Upper Triassic of New Mexico. Paläontol. Z. 79, 471-478 (2005).

12. Whiteside, J. H., Grogan, D. S., Olsen, P. E. \& Kent, D. V. Climatically driven biogeographic provinces of Late Triassic tropical Pangea. Proc. Natl. Acad. Sci. USA 108, 8972-8977 (2011).

13. Irmis, R. B. Axial skeleton ontogeny in the parasuchia (Archosauria: Pseudosuchia) and its implications for ontogenetic determination in archosaurs. J. Vertebr. Paleontol. 27, 350-361 (2007).

14. Sues, H.-D., Olsen, P. E., Carter, J. G. \& Scott, D. M. A new crocodylomorph archosaur from the Upper Triassic of North Carolina. J. Vertebr. Paleontol. 16, 34-41 (2003).

15. Wu, X.-C. \& Chatterjee, S. Dibothrosuchus elaphros, a crocodylomorph from the Lower Jurassic of China and the phylogeny of the Sphenosuchia. J. Vertebr. Paleontol. 13, 58-89 (1993).

16. Walker, A. D. A revision of Sphenosuchus acutus Haugton, a crocodylomorph reptile from the Elliot Formation (Late Triassic or Early Jurassic) of South Africa. Phil. Tran. R. Soc. B. 330, 1-20 (1990).

17. Brusatte, S. L., Butler, R. J., Sulej, T. \& Niedzwiedzki, G. The taxonomy and anatomy of rauisuchian archosaurs from the Late Triassic of Germany and Poland. Acta Palaeontol. Pol. 54, 221-230 (2009).

18. Nesbitt, S. J. The early evolution of archosaurs: relationship and the origin of major clades. Bull. Amer. Mus. Nat. Hist. 352, 1-292 (2011).

19. Clark, J. M., Xu, X., Forster, C. A. \& Wang, Y. A Middle Jurassic 'sphenosuchian' from China and the origin of the crocodylian skull. Nature 430, 1021-1024 (2004).

20. Holliday, C. M., Tsai, H. P., Skijan, J., George, I. D. \& Pathan, S. A 3D interactive model and atlas of the jaw musculature of Alligator mississippiensis. PLoS ONE 8, e62806; DOI:10.1371/journal.pone.0062806 (2013). 
21. Weinbaum, J. C. The skull of Postosuchus kirkpatricki (Archosauria: Paracrocodyliformes) from the Upper Triassic of the United States. PaleoBios 30 , 18-44 (2011).

22. Peyer, K., Carter, J. G., Sues, H.-D., Novak, S. E. \& Olsen, P. E. A new suchian archosaur from the Upper Triassic of North Carolina. J. Vertebr. Paleontol. 28, 363-381 (2008).

23. Irmis, R. B., Mundil, R., Martz, J. W. \& Parker, W. G. High-resolution U-Pb ages from the Upper Triassic Chinle Formation (New Mexico, USA) support a diachronous rise of dinosaurs. Earth Planet. Sci. Lett. 309, 258-267 (2011).

24. Green, J. L., Schneider, V. P., Schweitzer, M. \& Clarke, J. New evidence for nonPlacerias dicynodonts in the Late Triassic (Carnian-Norian) of North America. J. Vertebr. Paleontol. Programs Abstr. 25, 65-66 (2005).

25. Liu, J. \& Sues, H.-D. Dentition and tooth replacement of Boreogomphodon (Cynodontia: Traversodontidae) from the Upper Triassic of North Carolina, U.S.A. Vertebr. PalAsiatica 48, 169-184 (2010).

26. Heckert, A. B., Schneider, V. P. \& Fraser, N. C. Two new aetosaurs (Reptilia:Archosauria) from the Upper Triassic Pekin Formation (Deep River Basin: Newark Supergroup) of North Carolina and the phylogeny and distribution of aetosaurs. Geol. Soc. Am. Abstr. Programs 44, 233 (2012)

27. Nesbitt, S. J. et al. A new, nearly-complete skeleton of an early diverging crocodylomorph from the Late Triassic (late Carnian) of North America and high rates of morphological change prior to the end-Triassic extinction. J. Vertebr. Paleontol. Programs Abstr. 34, 195 (2014).

28. Ezcurra, M. D. Biogeographic analysis of Triassic tetrapods: Evidence for biotic provincialism and driven sympatric cladogenesis in the early evolution of modern tetrapod lineages. Proc. R. Soc. B 277, 2547-2552 (2010).

29. Barrett, P. M. et al. A paleoequatorial ornithischian and new constraints on early dinosaur diversification. Proc. R. Soc. B 281, 201411147; DOI:10.1098/ rspb.2014.1147 (2014).

30. Brusatte, S. L., Benton, M. J., Ruta, M. \& Lloyd, G. T. Superiority, competition, and opportunism in the evolutionary radiation of dinosaurs. Science 321, 1485-1488 (2008).

31. Ritchie, E. G. \& Johnson, C. N. Predator interactions, mesopredator release and biodiversity conservation. Ecol. Lett. 12, 982-998 DOI:10.1605/01.3010006385757.2009 (2009).

32. Turner, A. H. \& Nesbitt, S. J. [Body size evolution during the Triassic archosauriform radiation] Anatomy, phylogeny and palaeobiology of early archosaurs and their kin [Nesbitt, S. J., Desojo, J. B. \& Irmis, R. B. (eds)] [573-597] (Geol. Soc. Lond., London, 2013) DOI 10.1144/SP379.15.

33. Sookias, R. B., Butler, R. J. \& Benson, R. B. J. Rise of dinosaurs reveals major bodysize transitions driven by passive processes of trait evolution. Proc. R. Soc. B 279, 2180-2187; DOI:10.1098/rspb.2011.2441 (2012)

34. Zanno, L. E. \& Makovicky, P. J. No evidence for directional evolution of body mass in herbivorous theropod dinosaurs. Proc. R. Soc. B 280, 20122526 (2012).

35. Irmis, R. B. Evaluating hypotheses for the early diversification of dinosaurs. Earth Envir. Sci. Tran. R. Soc. Edinburgh 101, 397-426 (2011)

36. Smith, R. J. Allometric scaling in comparative biology: problems of concept and method. Am. J. Physiol. Regul. Integr. Comp. Physiol. 246, 152-160 (1984).

37. Reig, O. A. La presencia de dinosaurois saurisquios de los 'Estratos de Ischigualasto' (San Juan, Argentina). Revista de la Asociación Geológica Argentina 13, 257-270 (1958).

38. Clark, J. M., Sues, H.-D. \& Berman, D. S. A new specimen of Hesperosuchus agilis from the Upper Triassic of New Mexico and the inter-relationships of basal crocodylomorph archosaurs. J. Vertebr. Paleontol. 20, 683-704 (2000).

39. Harris, J. D., Lucas, S. G., Estep, J. W. \& Li, J. A new and unusual sphenosuchian (Archosauria: Crocodylomorpha) from the Lower Jurassic Lufeng Formation, People's Republic of China. Neues Jahrbuch Geol. Paläontol. Abhandlungen 215 47-68 (2000).

40. Walker, A. D. A revision of the Jurassic reptile Halopus victor (Marsh), with remarks on the classification of crocodiles. Geol. Mag. 105, 1-14 (1970).

41. Sues, H.-D., Nesbitt, S. J., Berman, D. S. \& Henrici, A. C. A late-surviving basal theropod dinosaur from the latest Triassic of North America. Proc. R. Soc. B 278 , 3459-3464 (2011)

42. Smith, N. D., Makovicky, P. J., Hammer, W. R. \& Currie, P. J. Osteology of Cryolophosaurus ellioti (Dinosauria: Theropoda) from the Early Jurassic of Antarctica and implications for early theropod evolution. Zool. J. Linn. Soc. 151, 377-421 (2007).

43. Barrett, P. M. \& Rayfield, E. M. Ecological and evolutionary implications of dinosaur feeding behavior. Trends Ecol. Evol. 21, 217-224 (2006).

44. Barrett, P. M. Paleobiology of herbivorous dinosaurs. Annu. Rev. Earth Planet. Sci. 42, 207-230 (2014).

45. Zanno, L. E. \& Makovicky, P. J. Herbivorous ecomorphology and specialization patterns in theropod dinosaur evolution. Proc. Natl Acad. Sci. USA 108, 232-237; DOI:10.1073/pnas.1011924108 (2010).
46. Farlow, J. O. Speculations about the diet and digestive physiology of herbivorous dinosaurs. Paleobiol. 13, 60-72 (1987).

47. Michell, J. S. \& Makovicky, P. J. Low ecological disparity in Early Cretaceous birds Proc. R. Soc. B 281, 1787 (2014)

48. Angielczyk, K. D., Roopnarine, P. D. \& Wang, S. C. Modeling the role of primary productivity disruption in end-Permian extinctions, Karoo Basin, South Africa. N. M. Mus. Nat. Hist. Sci. Bull. 30, 16-23 (2005).

49. Mitchell, J. S., Roopnarine, P. D. \& Angielczyk, K. D. Late Cretaceous restructuring of terrestrial communities facilitated the end-Cretaceous mass extinction in North America. Proc. Natl Acad. Sci. USA 109, 18857-18861; DOI:10.1073/pnas.1202196109 (2014)

50. Gauthier, J. A., Nesbitt, S. J., Schachner, E. R., Bever, G. S. \& Joyce, W. G. The bipedal stem crocodilian Poposaurus gracilis: inferring function in fossils and innovation in archosaur locomotion. Bull. Peabody Mus. Nat. Hist. 52, 107-126 (2011).

51. Nesbitt, S. J. The anatomy of Effigia okeeffeae (Archosauria, Suchia), theropod-like convergence, and the distribution of related taxa. Bull. Am. Mus. Nat. Hist. 302, 1-84 (2007).

52. Maddison, W. P. \& Maddison, D. R. Mesquite: A modular system for evolutionary analysis. Version 2.75 http://mesquiteproject.org (2008) Date of access: 20/07/ 2013

53. Goloboff, P. A., Farris, J. S. \& Nixon, K. TNT: tree analysis using newtechnologies http://www.zmuc.dk/public/phylogeny (2003) Date of access: 20/07/2013.

54. Bremer, K. Branch support and tree stability. Cladistics 10, 295-304 (1994).

55. Coddington, J. \& Scharff, N. Problems with zero-length branches. Cladistics 10 415-423 (1994)

56. Finden, C. R. \& Gordon, A. D. Obtaining common pruned trees. J. Class 2 255-276 (1986)

57. Long, R. A. \& Murray, P. A. Late Triassic (Carnian and Norian) tetrapods from the southwestern United States. New Mexico Mus. Nat. Hist. Sci. 4, 1-254 (1995).

58. Weinbaum, J. C. Osteology and relationships of Postosuchus kirkpatricki (Archosauria: Crurotarsi) [1-78] Unpublised master's thesis (Texas Tech University, 2002)

\section{Acknowledgments}

We thank A. Heckert for diversity data; W. Parker and M. Smith (PEFO), P. Holroyd and K. Padian (UCMP), A. Henrici and M. Lamanna (CMNH), J. Cundiff (MCZ), D. Brinkman and M. Fox (YPM), M. Norell and C. Mehling (AMNH) for access to specimens; R. Benson for matrix files; and P. Brinkman, L. Herzog for specimen preparation. Financial support provided by the Doris O. and Samuel P. Welles Research Fund (UCMP) and an Ernst Mayr Travel Grant in Animal Systematics (Harvard MCZ) to S.D., NC Museum of Natural Sciences, and NC State University. Free online versions of TNT and Mesquite provided by the Willi Hennig Society and the Free Software Foundation Inc.

\section{Author contributions}

L.Z. and S.D. jointly conceived the project, described fossil materials, analyzed the data, and wrote the manuscript with contributions from S.N and V.S. L.Z., S.D. and S.N. coded the specimen for phylogenetic analysis; L.Z. performed phylogenetic analyses; V.S. collected fossil materials.

\section{Additional information}

Supplementary information accompanies this paper at http://www.nature.com/ scientificreports

Competing financial interests: The authors declare no competing financial interests. Phylogenetic Data archived as Project 2125 at Morphobank (www.morphobank.org) Reprints and permissions information is available at www.nature.com/reprints How to cite this article: Zanno, L.E., Drymala, S., Nesbitt, S.J. \& Schneider, V.P. Early crocodylomorph increases top tier predator diversity during rise of dinosaurs. Sci. Rep. 5 9276; DOI:10.1038/srep09276 (2015).

This work is licensed under a Creative Commons Attribution 4.0 International License. The images or other third party material in this article are included in the article's Creative Commons license, unless indicated otherwise in the credit line; if the material is not included under the Creative Commons license, users will need to obtain permission from the license holder in order to reproduce the material. To view a copy of this license, visit http://creativecommons.org/licenses/by/4.0/ 